\title{
The research of water temperature model for bathtub
}

\author{
Shanghe $\mathrm{Chi}^{1, \mathrm{a}}$ \\ ${ }^{1}$ North China Electric Power University , Baoding 071003, China; \\ aletitiacsh@163.com
}

Keywords: Heat balance equation, Thermal conductivity, Heat exchange formula

\begin{abstract}
When there is no heat source,we analyze the downward trend of surface water and inner water by calculating heat dissipation and heat absorption.here are heat exchange between surface water and air,surface water and inner water,inner water and hot water,inner water and bathtub wall.They can be calculated through enthalpy difference formula,heat conduction formula and principle of minimum increase of entropy.Then, according to heat balance equation,relationship between flow rate of hot water and time is obtained in inner model.Relationship between temperature of surface water and time is obtained in surface model.Human action accelerates wind speed,we calculate new heat dissipation in evaporation.According to formula of thermal resistance of air layer, we can get thermal resistance of air layer.According to numerical analysis, we draw conclusions. When there is no heat source, the water temperature first decreases linearly,then tend to be gentle.Surface water drops faster than inner.
\end{abstract}

\section{Introduction}

In recent years, more and more people use the bathtub. They want to relax in the bathtub. However, the water in the bath will cool over time, reducing the satisfaction of the people. So we developed a model to make the bather's temperature constant. To meet this requirement, the bath water temperature fluctuations can not be too large. Therefore, according to the heat exchange formula ${ }^{[1]}$ and the heat balance equation, we can get the relationship between temperature of surface water and time and the relationship between flow rate of hot water and time.Their heat conduction relationships are shown in Figure 1.

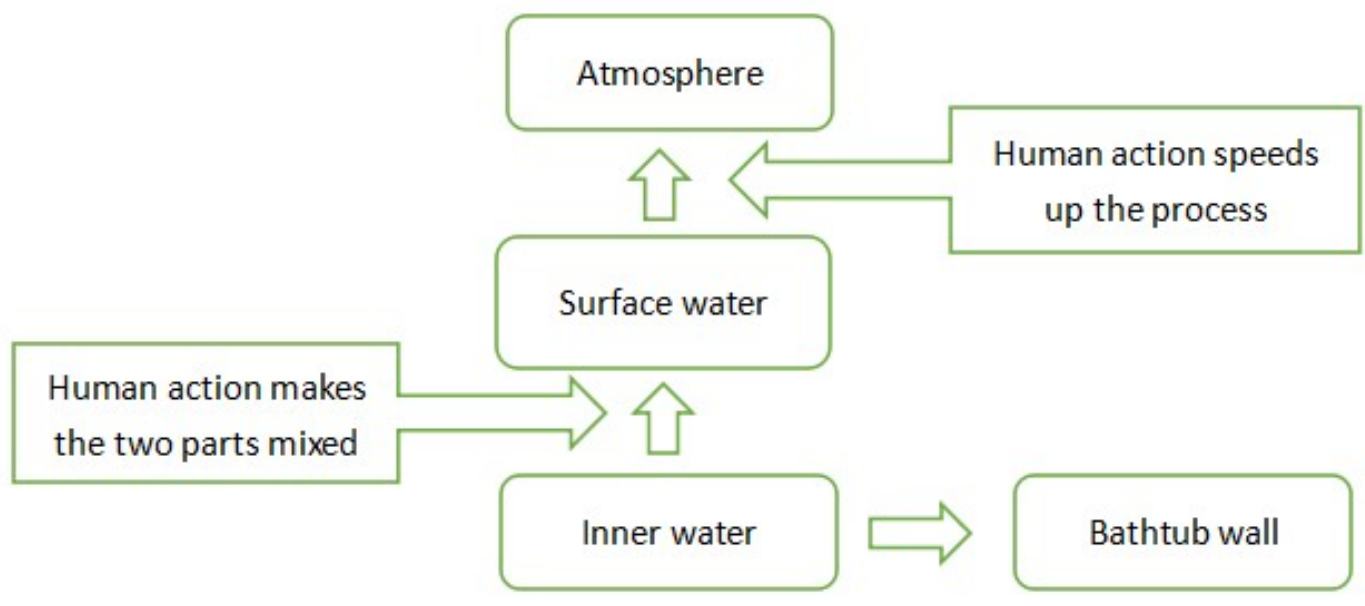

Fig.1 Heat transfer diagram

\section{Basic Model}

\subsection{Original temperature model}

In the original case, there is no external heat source. So there is heat exchange between the surface water and air , inner water and the bathtub wall.Because the heat dissipated from surface water to air is more than the heat dissipated from inner water to bathtub wall.The surface water and inner water produce temperature difference.So heat exchange between them also exist. 
Table 1 Model parameters

\begin{tabular}{|c|c|}
\hline Parameter & Meaning \\
\hline$Q c, Q e$ & The heat dissipated from surface water to air/ water evaporation \\
\hline Qs, $Q x$ & $\begin{array}{l}\text { The heat exchange between surface and inner water, The heat dissipated from inner } \\
\text { water to bathtub wall }\end{array}$ \\
\hline$A, F$ & Surface area ,Lateral area \\
\hline$f w, w$ & Function expressed by wind speed,Wind speed \\
\hline es, ea & $\begin{array}{l}\text { Air saturated vapor evaporating pressure near the surface of the water, The air } \\
\text { evaporation pressure above the water surface }\end{array}$ \\
\hline$c, k$ & Specific volume heat of water,Heat transfer coefficient of bathtub wall \\
\hline$m s, m x$ & Quality of surface/inner water \\
\hline$T, T a$ & Temperature,Temperature of air \\
\hline$T w, T x$ & Temperature of surface/inner water \\
\hline$t, \varphi$ & Time,Relative humidity \\
\hline$P n, P b$ & partial pressure of vapor in the air,Saturated vapor pressure at the same temperature \\
\hline
\end{tabular}

\subsubsection{Surface model.1}

The heat dissipated from the surface water in the bathtub to air is mainly divided into two parts: convection heat dissipation and evaporative heat dissipation.According to the convective heat transfer formula ${ }^{[2]}$ between water and air,we can obtain the heat dissipated to air is

$d Q_{c}=0.47 f_{w} *\left(T_{w}-T_{a}\right) * d A$

$f_{w}=9.2+0.46 w^{2}$

and the heat dissipated in water evaporation is

$$
\begin{aligned}
& d Q_{e}=f_{w} *\left(e_{s}-e_{a}\right) * d A \\
& e_{s}=\exp \left[20.85-5278 /\left(T_{w}+273.3\right)\right] \\
& e_{a}=P_{n} * 1000 /(13.6 * 1000 * 9.8) \\
& P_{n}=\varphi^{*} P_{b}
\end{aligned}
$$

Because there is heat exchange between the two layers of water.And the temperature of surface water is lower .The surface water can absorb heat from inner water.Then,we can get ${ }^{[3]}$

$d Q_{c}+d Q_{e}-d Q_{s}=c^{*} m_{s} * d T / d t$

So,we can get the relationship between temperature of surface water and time.

\subsubsection{Inner model.1}

The heat dissipated from the inner water in the bathtub to bathtub wall.According to the convective heat transfer formula between water and bathtub wall,we can obtain the heat dissipated to bathtub wall is

$$
d Q_{x}=k *\left(T_{x}-T_{a}\right) * d F
$$

Because the temperature of inner water is higher.The inner water can release heat to surface water.So, we can get

$d Q_{x}+d Q_{s}=c^{*} m_{x} * d T / d t$ 
So,we can get the relationship between temperature of inner water and time.

\section{Numerical Computation}

We determine values for some parameters. ${ }^{[4]}$

We consider the volume of the people is $60 \mathrm{~L}$ and the volume of the bathtub is 360L.Then, the surface area is $0.975 \mathrm{~m}^{2}$, the lateral area is $1.5 \mathrm{~m}^{2}$. We define the quality of surface water is $5 \%$ of the total amount of water. Wind speed is $0.4 \mathrm{~m} / \mathrm{s}$. Temperature of surface is $40{ }^{\circ} \mathrm{C}$, inner water is $39^{\circ} \mathrm{C}$, air is $25{ }^{\circ} \mathrm{C}$. We think the relative humidity is $70 \%$. $C_{i}=C_{w}=0.97, C_{0}=5.67$. We taking heat preservation into account, $\theta=1$.

Saturated vapor pressure at the $25^{\circ} \mathrm{C}$ is $31.8 \mathrm{mmHg}^{[6]}$. And heat transfer coefficient of

bathtub wall is $4.18 \mathrm{~kJ} /\left(\mathrm{m}^{2} . \mathrm{h} .{ }^{\circ} \mathrm{C}\right)^{[7]}$.Specific volume heat of water is $4.2 \mathrm{~kJ} /\left(\mathrm{kg}^{\circ} \mathrm{C}\right)$. According to the Model,we can obtain the heat dissipated from surface water to air is $3841.74 \mathrm{~J} / \mathrm{min}$, to water evaporation is $20791.7632 \mathrm{~J} / \mathrm{min}$.Similarly,the heat dissipated from inner water to bathtub wall is $1567.5 \mathrm{~J} / \mathrm{min}$.So,we can get the relationship between temperature of surface water and time like the Figure2(a) ,the relationship between temperature of inner water and time like the Figure2(b).

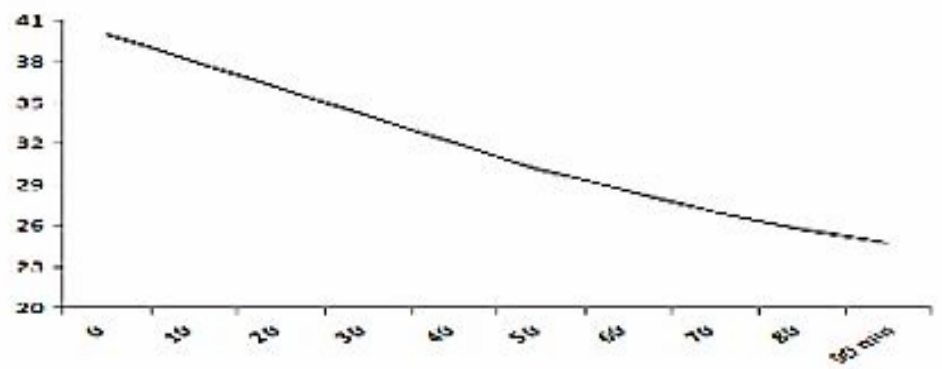

a

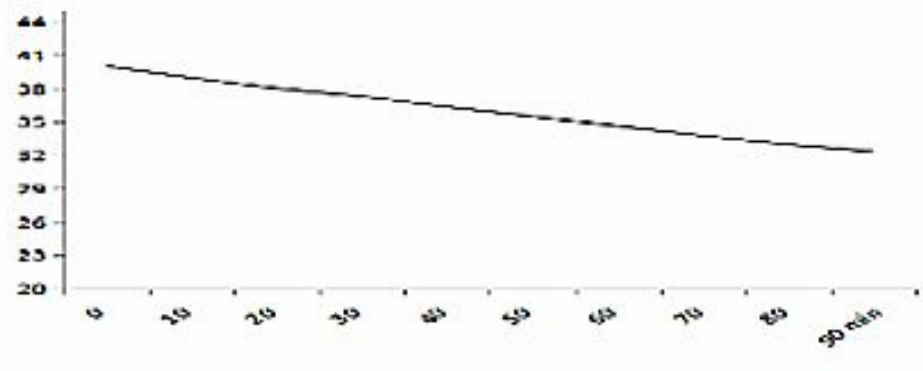

b

Fig.2 Water temperature without heat source

\section{Summary}

According to the data ,we can see that in the original state, the temperature of the bath water decreased linear at the beginning and later tended to be gentle. And the surface temperature decreased significantly faster than the inner. That evaporative and air convection heat dissipation is much greater than the wall.

\section{References}

[1] Jinxiang Liu,Jian Zhao. Surface water source heat pump water temperature model and water temperature simulation analysis .Proceedings of the Symposium on ventilation technology, 2007

[2] A Bejan. Entropy Generation through Heat and Fluid. John Wiley \& sons, New York,1982 
[3] A Bejan. Entropy Generation Minimization. Florida. CRC Press,1996

[4] Weijian Tan. Discussion on the influence of air in building materials on the thermal properties of materials. 